\title{
Written scientific discourse beyond words
}

\section{Claude Sionis}

\section{OpenEdition

\author{
Journals
}

Electronic version

URL: http://journals.openedition.org/asp/3198

DOI: 10.4000/asp.3198

ISSN: 2108-6354

\section{Publisher}

Groupe d'étude et de recherche en anglais de spécialité

\section{Printed version}

Date of publication: 1 December 1997

Number of pages: $357-371$

ISSN: 1246-8185

\section{Electronic reference}

Claude Sionis, «Written scientific discourse beyond words », ASp [Online], 15-18| 1997, Online since 20 November 2012, connection on 19 April 2019. URL : http://journals.openedition.org/asp/3198 ;

DOl : 10.4000/asp.3198

This text was automatically generated on 19 April 2019

Tous droits réservés 


\title{
Written scientific discourse beyond words
}

\author{
Claude Sionis
}

\section{Introduction}

1 The present paper is based on the first 30 written papers submitted in English by NS and NNS researchers to the scientific committee of an international conference in mechanical engineering held in Nantes in 1996. ${ }^{1}$ What is studied in this paper is the material representation of a supposedly coherent intellectual activity as a physical assembly of verbal materials (VM) and non- (or rather partially-) verbal materials (NVM) within a cohesive type of discourse.

2 What triggered the EST researcher's interest was the realisation that, in the domain concerned which involved computer science, mechanics, system engineering, materials behaviour, etc., the researchers used NVM as their focal points and indeed the very backbone of their papers. Their verbal discourse was created and organised to develop and comment on NVM and not the other way around. NVM were definitely not used to "illustrate" a predominantly verbal type of communication, they were the very subject and the main mode of communication. Although not always spoken in words, there was no doubt about the singleness and integration of the discourse used.

Quirk in his introduction to Halliday \& Hasan (1976: i ) notes that:

involvement beyond the sentence involves a complex interplay of linguistics with other concerns such as rhetoric, aesthetics, pragmatics, stylistics.

4 To a certain extent NVM relate to or communicate with each other when the reader associates them visually or uses verbal signs which act as a meaningful counterpoint between several NVM.

5 The musical analogy can go beyond a strictly formal accounting of the respective roles of VM and NVM. As Ducrot \& Todorov (1972: 137) observe, music, like visual representation, is a code: 
all the elements of a composition (pitch, volume, tone, etc.) are related to one another, but they do not mean anything (...) a majority of the meaningful systems we live with are hybrid: they are codes, sign-systems, and symbolic systems at the same time.

6 Ducrot and Todorov also add that only verbal language can speak of itself, build up sentences which do not refer to reality, use words hitherto unknown of a linguistic community and yet be understood through context, e.g. by using original metaphors. These are the characteristics of secondarity which in theory belong to verbal language only. However, if NVM need VM to establish discursive cohesion (lexico-syntactic, semantic and pragmatic) between themselves, they can illustrate via symbolic code which is as essential a component of scientific communication as verbal representation. This is also evidence of some "metavisual" quality in NVM which can describe other non-verbal representations by visual illustration only. Thus complex pictorial representations of whole processes, systems or equipment are often broken down into smaller representations of their individual constituents.

\section{Pragmatic/rhetorical connectedness}

7 The pragmatic or rhetorical processing of VM/NVM discourse is modest in its formal manifestation: establishing connectedness between VM and NVM, i.e. creating complex discursive units out of simple ones It is also ambitious in its aim which is of ultimately establishing conceptual coherence.

8 Like semantic cohesion, connectedness is a constituent of thematic progression and continuity. However, because it is manifested by grammatical markers like but, and, because, so, however, yet, also, besides, etc., connectedness does not only contribute to grammatical cohesion but also to the strategic ordering of discursive units to fulfil a rhetorical purpose. This purpose is to win over the reader/hearer to the validity of the demonstration presented by the scientific paper. The gradual introduction of hybrid VM/ NVM discursive units results in different types of connectedness devices when e.g. NVM open or close those discursive units.

9 In a field like the relative use of VM and NVM, in which there is no agreed framework of analysis, it is difficult to resist the logocentric temptation of assimilating the VM-NVM opposition to other better known strictly linguistic oppositions. One such opposition is the descriptive vs. procedural role assigned to some referential expressions in pure verbal communication.

10 Those referential expressions whose lexical meaning is sufficient to determine their referents have a sort of referential autonomy and can be said to have "descriptive meaning", e.g., The numerically-controlled lathes used in manufacturing technology.

11 The referential expressions which have no referential autonomy and whose function varies relative to their linguistic environment are said to have "procedural meaning". Among them are certainly those grammatical terms very loosely called "connectors" and which are associated with no specific context. One of the characteristics of connectors is to convey a set of instructions on how to interpret utterances.

12 The following examples taken from another paper in our corpus show three instances of the use of then making it very difficult to isolate any common-core meaning among them: 
1) "The general method is explained in paragraph 2. We then describe the improvements we have made in paragraph 3 and finally give the numerical gains in paragraph 4."

2) "On the other hand, when there are potentially two colinear normals, closed curves cannot be excluded. It is then necessary to split the two surfaces until the closed curves are decomposed into open curves."

3) "The Marquardt method was then the only valid one, nowadays Hohmeyer's detection test used with convex pyramids is to decompose closed curves into open ones." (NNS unamended passage) (Daniel \& Lucas 1996)

13 A term can be said to have "procedural meaning" when what is linguistically associated with it is not a lexical meaning but a set of instructions called "procedure". The three instances of then are interchangeable structurally but not semantically because they each depend closely on a network of sense and a specific linguistic context which give them referential meaning. Milner (1989) defines those terms which have descriptive meaning as being "referentially autonomous". In the three examples given, then resorts to several linguistic factors to determine its referents, the most obvious factor being its anaphoric function.

If our lexico-syntactic markers can be said to belong to the language system and to participate in the conceptual encoding of sentences, markers of connectedness belong rather to the use of this system and participate in the procedural encoding of sentences. Non-linguistic devices like, among others, "visual" NVM, can be said to participate in the inferential, rather than descriptive, representation of concepts because of the level of implicit information they include, but they also take part in the procedural encoding of sentences. This set of relations between linguistic code and non-linguistic representation can be illustrated as in figure 1 .

Figure 1

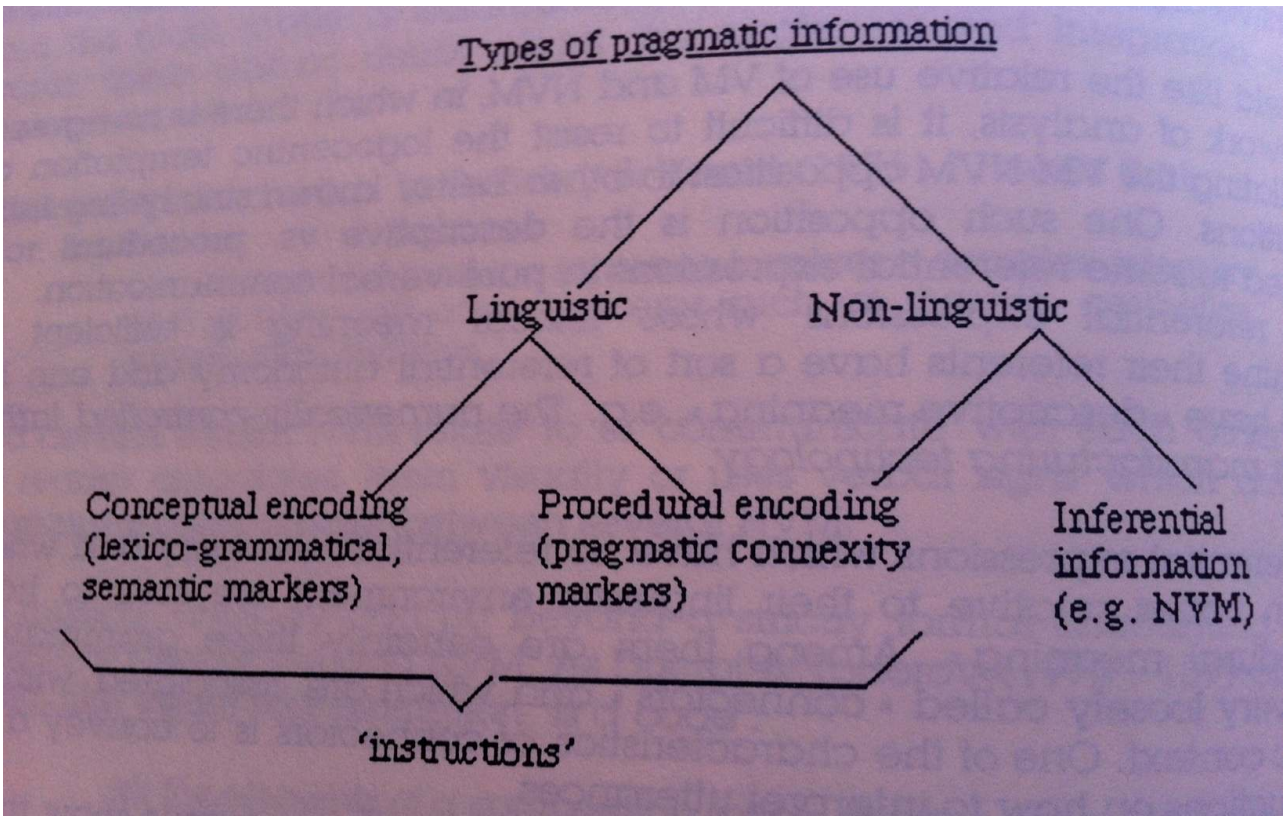

Adapted from Moeschler \&Reboul (1995)

A factor affecting the choice of connectedness markers in our corpus is the varying level of verbal complexity exhibited by different discursive VM/NVM units. These pragmatic markers can range from the conventional single-word type (however, yet, also, etc.) to 
complete paragraphs made up of strictly rhetorical or "strategic" sentences, like the following passage by two NNS researchers. In it, the authors both make amend for a preceding over-complex text+diagram unit and apologise in advance for an upcoming even more elaborate passage:

For the mechanical problem, our demonstration concerned the formulation of the total energy function of the deformed glass body using the three-field mixed approach. This could not be conveyed other than through the above-description. An acceptable evaluation of the pressure field and of the stress field in the deformed glass volume can only be shown again using the same mode of demonstration which can be understood with prior knowledge of (source quoted). (Text of original paper rejected by IDMME' 96 scientific committee on account of "inappropriate content and form")

Not losing the reader's confidence and agreement seems to be another reason why pragmatic markers are used. What Widdowson (1979: 175) calls "phatic communion" is also to be associated with Grice's co-operative principle (Grice 1975: 45) by which encoders and decoders of general or scientific discourse must maintain some sort of uninterrupted, albeit fluctuating, communication link. This is particularly necessary when input and intake are at variance, i.e., when new information has not been adequately introduced by older information.

In the case of VM/NVM discourse, Grice's four maxims, which make up the co-operative principle and on which pragmatic connectedness depends so closely, are not necessarily verified. As an aid to memory, the maxims are:

Quantity: make your contribution as informative as possible. Do not be more informative than required.

Quality: Do not say what you believe to be false. Do not say that for which you lack adequate evidence.

Relation: Be relevant

Manner: Be perspicuous. Avoid obscurity and ambiguity. Be brief, orderly, and polite.

In the corpus studied, the 151 samples of non-verbal or partially-verbal materials carried information far in excess of that needed for the purpose of the VM with which they were associated.

Interestingly, the reverse was not true, and when questioned by the EST teacher about the relative scarcity of text relative to the number and richness of associated NVM, three authors pointed out that this occurred mostly when the functioning of a mechanism was described. For them, partially labelled or even mute NVM were the best adapted means of suggesting the kinetic characteristics of mechanisms. At least two teams of researchers underlined the fact that since their discourse was peer-oriented, other specialists should normally have no difficulty in extrapolating the motions of mobile parts and assemblies from static non-verbal representation.

The other three maxims, especially the second, on truth and the ethical aspect of communication, go beyond pragmatic connectedness as a device of strictly formal text organisation.

21 Scientific discourse whose main purpose is to assert a personal "new" truth can be considered as being composed of two basic strands. One strand is personal and "intratextual" (self-referring) and is represented by the researcher's own line of reasoning. The other strand is "intertextual" and concerns all exterior reference 
(quotations, mathematical theorems and formulae, previous well-established approaches, etc.).

In the case of scientific discourse which aims at conveying a given representation of knowledge, the intertextual element represents the unquestioned solid truths which are rhetorically used as the basic discursive elements on which to build one's own discourse, as if it were necessary to ground unsteady truths on to more solid ones to ensure credibility and acceptability.

In the case of hybrid VM/NVM discourse, the various types of semiotic modes, verbal, partially-verbal, and non-verbal, are used in the two strands mentioned, and the difficulty lies in the basically different ways in which VM and NVM carry information. Because of their nature, and at least in the specialised field of the corpus, VM, and especially the more "literal" ones among them, have a limited and unequivocal nature. This is in accordance with Grice's fourth maxim which advocates clarity and simplicity and is even more evident for the intertextual established truths and reference sources.

On the other hand, NVM, and especially the more "visual" ones, lend themselves to a multiplicity of uncontrolled and equivocal interpretations. This results in writers having a range of different rhetorical attitudes towards their VM/NVM discourse. Dense and potentially ambiguous or equivocal NVM are verbally "oriented" and interpreted, sometimes at great length, by VM. The reader's understanding is guided by devices like the underlined pragmatic markers in the following passage:

The first lines in table 6 show the distance errors of $\mathrm{X}$ axis and $\mathrm{Y}$ axis after compensating. To measure the positioning accuracy among any points in 3-D space, we used a ball/bar system and the results are to be read in the next three lines. Please note that the remaining lines give results that can be extrapolated from traditional methods using laser measuring equipment. (NNS unamended text) (Shon et al. 1996)

One of the many strategies used by researchers for achieving peer-acceptability (Sionis 1995) is to submit blunt or categorical verbal statements to varying degrees of modality and to mitigate them by using lexical and grammatical hedges. For this purpose, adverbs ( probably, presumably, tentatively, etc.), verbs (believe, appear, seem to, try to, etc.) and many other devices are used. This aspect has been studied thoroughly by a number of authors (Salager-Meyer 1994; Dudley-Evans 1994) and needs not be laboured any further.

What is also achieved between VM and NVM in the corpus is some form of translation procedure, not between two different languages, but rather between two semiotic modes, much in the way a computer internal system manages, through the use of "translators", to make information initially acquired via a specific application readable via another application. Some lesser characteristics of the original information are sometimes lost in the translation process but this does not really endanger global understanding. An example of this phenomenon is given in Fig. 2 and the subsequent verbal development it generates. 


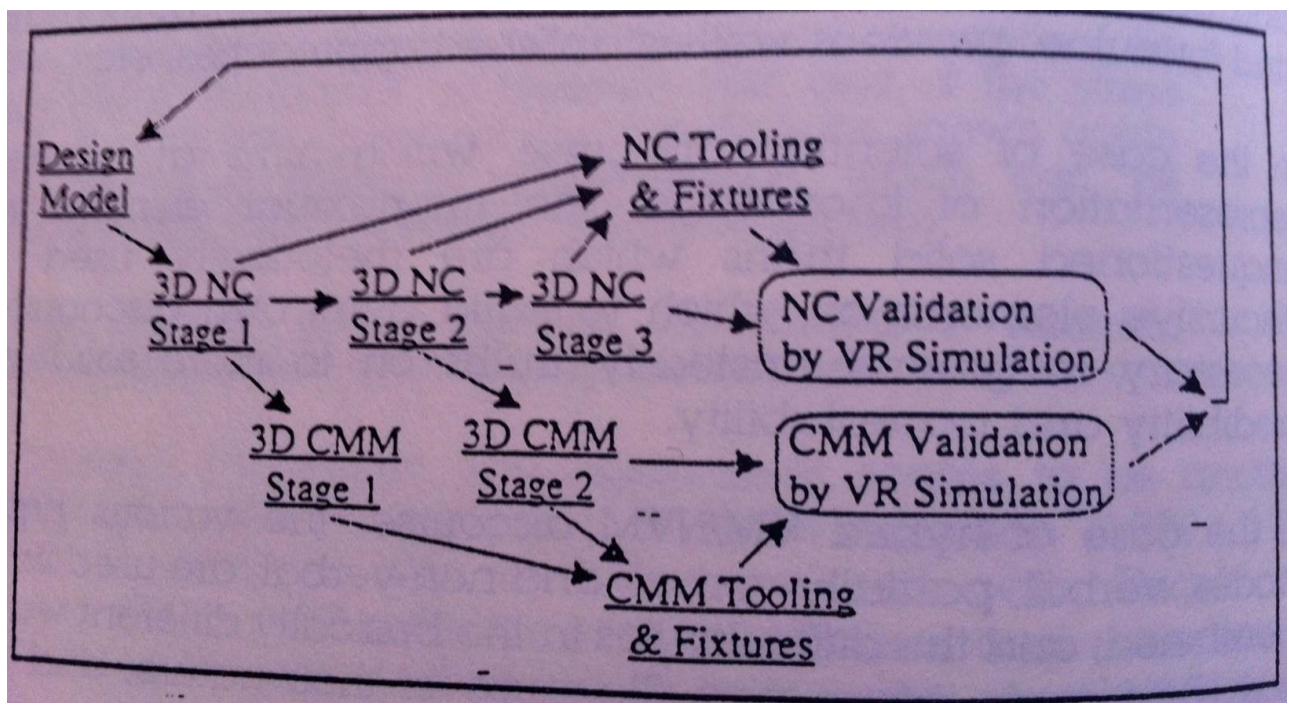

ModellingNC \& CMM Capability Closes the Loop with Design

From Bennet (1996)

This particular NVM associates time and space notions in rather fuzzy fashion, but nevertheless achieves its main purpose of presenting $\mathrm{CN}$ and $\mathrm{CMM}$ as parallel programming and validation actions. These modelling actions unfold in two or three stages and retroactively influence the design model. This partially verbal material is a sort of diagrammatic translation of a short preliminary passage which runs as follows:

With an accurate 3D design model it is possible to choose and appropriate stock model and define the stages of manufacturing in 3D (see Fig. 4). These 3D definitions can then be used to create the cutter path for each stage. Furthermore if a 3D solid design is created for the fixture then it is possible to perform a full kinematic simulation of the machining process and fully validate the $\mathrm{NC}$ program prior to cutting metal. (Bennet 1996)

The topic thus presented in VM/NVM complementary fashion is then developed as linear text over three full pages. What is interesting to note is that in the translation process from purely verbal to partially verbal representation, the fact that simulations were obtainable in 3D and the direct operational consequence of this (to create the cutter path for each stage) are somewhat lost in the NVM. However, what the NVM conveys more immediately is the associated time-space dimension and the fact that both $\mathrm{NC}$ and $\mathrm{CMM}$ validations are submitted to VR (virtual reality) simulation.

A last point here: contrary to unspecialised communication, it is more often the verbal element which, in the corpus samples of VM/NVM scientific communication, carries unequivocal information and not the pictorial representations. In this respect, the samples of scientific communication, although belonging to a hybrid semiotic system, can be said to be essentially symbolic, much like, in another less ambitious but essential domain, road-signs carry both elementary pictograms and single-word verbal messages ("Stop", "Yield", etc.).

If in the case of road-signs the verbal message is kept to a minimum, this is not only for reasons of space but because pictograms, if carefully drawn, should carry only 
unequivocal information; usually the nature of danger is conveyed pictorially, and the attitude to have relative to this danger is transmitted verbally. This appears to exemplify the respective complementary roles of VM and NVM as a hybrid communication medium.

For road-signs and scientific VM/NVM communication, the aim is first and foremost to convey information efficiently, unequivocally and fast. The main difference between the two VM and NVM channels is the continuity of meaning which exists in the latter and which characterises a text or a discourse. This is what Halliday and Hasan meant when they wrote:

a text is a unit of situational-semantic organisation: a continuum of meaning-incontext, constructed around the semantic relation of cohesion. (Halliday \& Hasan 1976: 25)

\section{Rigid and flexible discourses}

As already seen, communication in the "hard" sciences can be considered as being composed of two strands; an already established "solid-truth" discourse and the personal discourse of the researcher wishing to assert his own truth; the latter relying on the former in the hope of gaining legitimacy and acceptability. Culioli (1990) also describes specialised discourse as being composed of "stable" elements, like mathematical theorems, and of "pliable" (déformable) elements represented by the natural language of argumentation and to which language analysis can actually be applied (Petit 1994).

Benveniste (1966) identifies two main orientations in interactive discourse: what he calls "narration" (récit) is an utterance in which "utterer" and "co-utterer" (interlocutor), time and place of the utterance, are not identified by any marker. Discourse (discours), on the other hand, is any instance of written or oral discourse relative to its situation of utterance, in which markers of modality and deictics can be identified.

A parallel can be drawn between the rigid, "solid truth", and timeless discourse existing as background to communication in most hard sciences and Benveniste's notion of "narration" which is not grounded in the reality and the "now" of the discourse being specifically developed by a researcher. Likewise, this personal discourse may correspond to Benveniste's definition of an "actualised" and flexible form of communication.

This diversification of communication into "rigid" and "flexible" types of discourse fits our model of VM/NVM hybrid discourse, as it underlines the necessary semantic complementarity between the two semiotic modes.

When a researcher writes: "the curve gives a minimum indication of 58 ", the information is compatible with an accompanying graph showing the curve hitting the 60 index mark. In the first mode, information is conveyed in a non-literal and "flexible" way, in the second, information is transmitted non-verbally and pragmatically, in a literal and "rigid" way. This is also in accordance with discourse laws, and more especially with Ducrot's law of understatement (loi de litote) according to which we can

interpret utterances as meaning more than what their literal signification is

(Ducrot 1972: 137, my translation).

Incidentally, the example given, although plausible, was made for the purpose of the demonstration; we may assume that the scientist's attitude is more often to follow another discourse law, that of "exhaustivity", which echoes Grice's first maxim of quantity and prescribes that 
the speaker gives the strongest information s/he has on the subject, and which is

likely to be of interest to the addressee. (Ducrot 1972: 134, my translation). gives an indication of 60 ", but it would have been up to the non-verbal graph to imply a concept like e.g. "readings of 58 and 59 are observed as happening at + time indication". We can observe here that there is more often semantic coincidence between the two semiotic codes in the corpus. If the VM explicitly states "the curve rises up to 58", then the NVM shows:

Figure 3

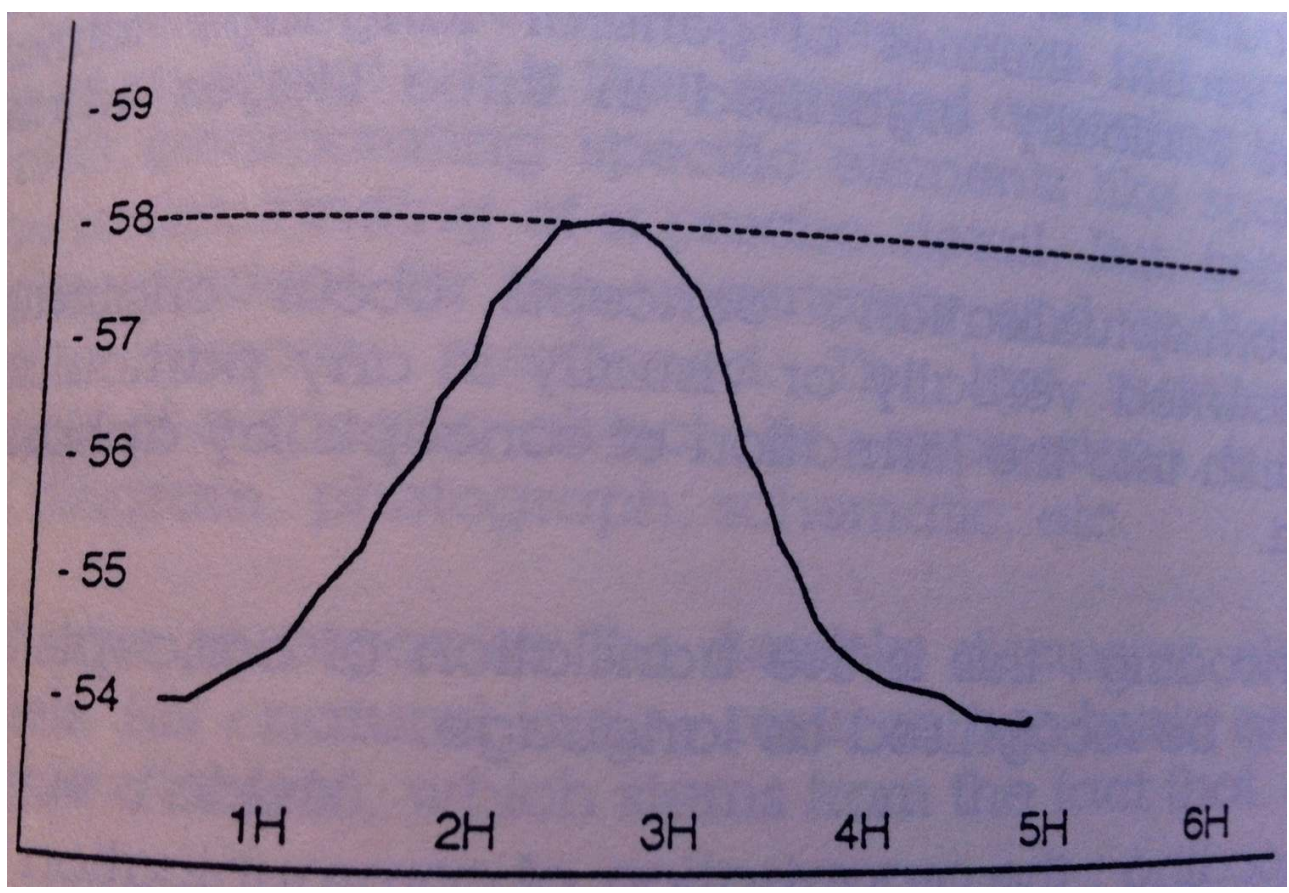

The contribution of the NVM is both explicit and implicit: it reinforces explicitly the information conveyed initially, and often in a "flexible" way, by the VM: the curve is actually shown as rising up to the 58 mark, and this is a result of the focusing effect of the VM placed before the NVM. It is also implicit: in this particular instance, the bell-like shape of the curve is also indicated, as well as information about the type of process: rapid, slow, iterative, step-like, etc.

Hybrid VM/NVM discourse then seems to be partaking in the dual nature of scientific communication which is composed of both "rigid" and "flexible" communication units. Some stretches of discourse would be unalterable because of one-to-one correspondence between concept and form, others would be flexible because of the part played in them by modality, adjustable frames of reference, writer's subjectivity, etc.

\section{Literal and non-literal components}

Under the "literal" heading we may put all unalterable elements like mathematical laws, theorems and formulae, but also all unequivocal NVM like self-explanatory diagrams or flow-charts. 
\& Todorov (1972: 40) write:

As far as glossematics (Hjemslev's theory) gives pride of place to "form" devoid of any semantic reality, it places "function", and the role of language in communication, in the background because this role is linked to substance, i.e. semantic reality. But in so doing it makes it possible to compare natural languages with other functionally and materially very different languages. into "conformable" languages when substance and form coincide formally, e.g. the formal system of mathematics in which concepts and their representations are unequivocal.

Hjemslev speaks of "connotation" when the signifying element in a language is the very choice of this language to express a given concept. In the case of our literal/non-literal discourse, the choice of a non-literal mode like a complex partially-labelled diagram is a connotative discursive unit. This indirectly signals an area of uncertainty or of conscious or unconscious potential developments within an otherwise strictly-ordered literal line of reasoning represented by verbal language.

For Halliday \& Hasan:

Like other semantic relations, cohesion is expressed through the stratal organisation of language. Language can be explained as a multiple coding system comprising three levels of coding, or "strata": the semantic (meanings), the lexico- 
grammatical (forms), the phonological and orthographic (expressions). Meanings are realised (coded) as forms, and forms are realised in turn (recoded) as expressions. (1976: 5) observe, the three components exist in all types of semiotic systems, and have been studied in their time by language analysts of the neo-positivist and logicist schools (Peirce, 1958 [1931]; Morris, 1938, Carnap, 1942) as an ordered three-layered process. The study of syntax (the relations between signs) always came before that of semantics (the 
relations between words, syntagms or phrases and the objects of the world), which in turn preceded that of pragmatics (the relations between signs and their interpreters). Each of the three components was considered as an independent and autonomous module, and e.g. the informational content of an utterance could be fully identified only after exhaustive syntactic description of this utterance.

The following diagram adapted by Moeschler and Reboul from Anscombre and Ducrot (1983) gives a more detailed idea of this analysing process.

Figure 4

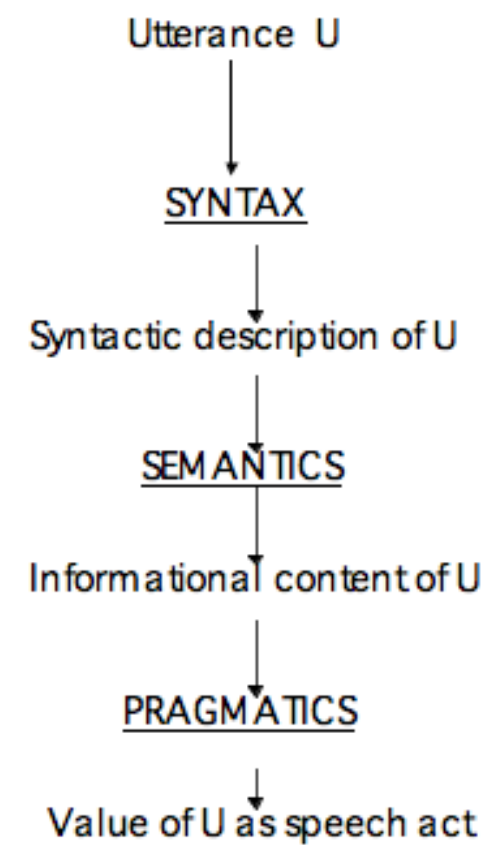

Adapted from Anscombre \& Ducrot (1983)

61 From analysis of the papers in the corpus, we can argue that in hybrid discourse, linguistic and non-linguistic integration devices operate in conjunction or in alternation, depending on the nature of the modes of presentation to be integrated, but definitely not as a consecutive process. There is no primacy among the syntactic, semantic or pragmatic treatments. What we have could be called "semantic purpose" in the sense of the writers keeping in mind at all times the meaning to be conveyed as the ultimate purpose of their demonstration. They would then press into service any cohesion, integration and rhetorical device likely to serve this purpose best in a given discourse situation.

Scientific communication involves both the conveyance of new information, and the necessity to discuss circumstances and conclusions among peers to further advance knowledge. The non-reciprocal transmission of the "rigid" literal elements of discourse, and the dialogic transmission of the "flexible" non-literal elements can then be included in the final VM/NVM product.

Although all information transmitted in writing is of a non-reciprocal nature, the term here means that even when the same information is given in oral form, there is little possible space for discussion and language manipulation. 
On the other hand, the non-literal "flexible" elements of discourse are conveyed in dialogic manner: there is space in them for both dialogue between addresser and addressee and for language interpretation, as there is no one-to-one correspondence between concepts and the signs used to express them. My model of analysis can then be summed up in the following (predominantly verbal!) diagram .

Figure 5: Model of hybrid discourse integration process

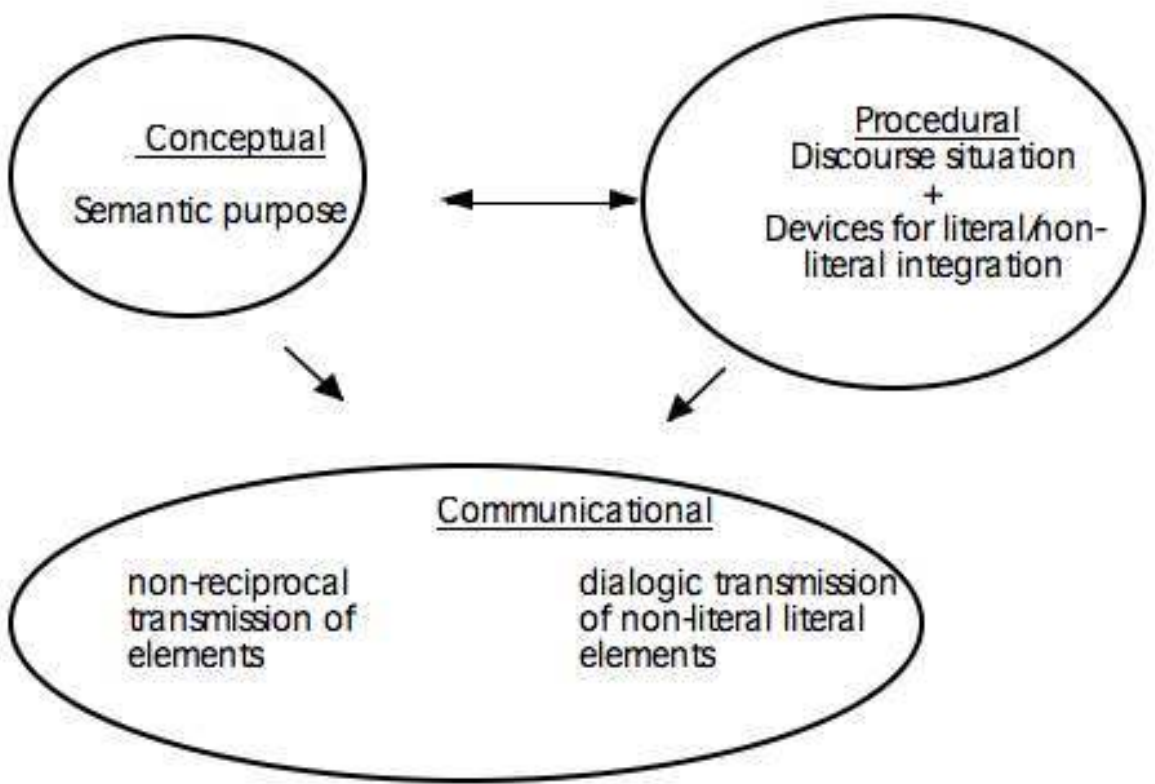

\section{Conclusion}

The issue of the integration of dissimilar components within the written discourse of science goes certainly further than what the present study has attempted to develop. It covers subjects and research domains as varied and vast as semiotics, mental representation, pragmatics, and cognitive science, among many others.

It is hoped that the few following observations based on a corpus in mechanical engineering will prove useful to EST/EAP teachers and researchers studying other fields of specialisation.

To parallel the metalinguistic quality of verbal language, NVM can be said to have a "meta-visual" quality and to exhibit some characteristics of secondarity when they help describe other non-verbal representations by visual illustration only. Linguistic markers of connectedness (a neutral word not to say "coherence" or "cohesion") belong to the use of the language system and participate in the procedural encoding of sentences, whereas non-linguistic devices like visual NVM participate in the inferential representation of concepts because of the level of implicit information they include.

Verbal materials generally convey information of an unequivocal nature, whereas nonverbal materials lend themselves to more equivocal interpretations. Co-existing VM and NVM imply some sort of translation procedure between them to enable the reader to 
check and cross-check the truth or content of the same type of information via several different media.

General discursive coherence is obtained in scientific communication by first establishing cohesion between dissimilar discursive elements. Beyond the VM/NVM distinction, literal and non-literal units must supplement one another if scientific discourse is to be considered also as communication, and not simply as the mere conveyance of information. Implicit and non-literal elements are unavoidable communicative constituents because they introduce in scientific discourse the dialogic dimension which is an essential factor in the evolution of concepts.

\section{BIBLIOGRAPHY}

Anscombre, J.C. \& O. Ducrot.1983. L'argumentation dans la langue. Bruxelles: Mardaga.

Bennet, G.R. 1996. “Manufacturing capability modelling for product design”. In IDMME'96

Proceedings, vol.1.

Benveniste, E. 1966. Problèmes de linguistique générale I. Paris: Gallimard.

Carnap, R. 1942. Introduction to Semantics. Cambridge, MA: MIT Press.

Culioli, A. 1990. Pour une linguistique de l'énonciation. Vol. 1. Gap: Ophrys.

Daniel, M. \& M. Lucas. 1996. “Towards declarative geometric modelling in mechanics. In IDMME'96 Proceedings, vol.1.

Ducrot, O. \& T. Todorov. 1972. Dictionnaire encyclopédique des sciences du langage. Paris: Points/ Seuil.

Dudley-Evans, T. 1994. "Academic text: The importance of the use and comprehension of hedges". ASp 5-6, 131-139.

Grice, H.P. 1975. "Logic and Conversation”. In Cole and Morgan, Syntax and Semantics Vol. 3: Speech Act. New York: Academic Press.

Grize, J.B. (ed.). 1984. Sémiologie du raisonnement. Bern: Lang.

Halliday, M.A.K. \& R. Hasan. 1976. Cohesion in English. London: Longman.

Hjemslev, L. 1968. Prolégomènes à une théorie du langage. Paris: Minuit.

Milner, J.C. 1989. Introduction à une science du langage. Paris: Seuil.

Moeschler, J. \& A. Reboul. 1995. Dictionnaire encyclopédique de Pragmatique. Paris: Seuil.

Morris, C. 1938. Foundations of the Theory of Signs. International Encyclopedia of Unified Sciences 1/2. Chicago: University of Chicago Press.

Peirce, C.S. 1958 [1931]. Collected Papers. Vol. 1-8. Cambridge: Harvard University Press.

Petit, M. 1994. "Le fond et la forme. Réflexion sur les limitations culturelles de la manipulation

linguistique en langue de spécialité: l'anglisticien et le discours scientifique”. ASp 5-6, 1-9. 
Salager-Meyer, F. 1994. "Hedges and textual communicative function in medical English written discourse”. English for Specific Purposes 13/2, 149-170.

Shon, J.W. et alii. 1996. "A general method for improving the volumetric positioning accuracy of CNC machine tools”. In IDMME'96 Proceedings I.

Sionis, C. 1995. "Communication strategies in the writing of scientific research articles by nonnative users of English". English for Specific Purposes 14/2, 99-113.

Widdowson, H.G. 1979. Explorations in Applied Linguistics. Oxford: Oxford University Press.

\section{NOTES}

1. Integrated Design and Manufacturing in Mechanical Engineering (IDMME '96), April 15-17, 1996. École Centrale de Nantes, France. (Proceedings available from ECN Publishing Department, 1 rue de la Noe, 44072 Nantes Cedex 03, France)

\section{ABSTRACTS}

Written scientific discourse, especially in engineering, technology and various other fields of the hard sciences, often resorts to partially verbal or non-verbal elements in the representation of knowledge. These elements co-exist within or alongside blocks of solid text. The article looks at some aspects of the dynamics of integration between dissimilar components and the specificity of the discourse they generate. The notions of pragmatic/rhetorical connectedness, rigid and flexible discourses, and literal or non-literal modes of exposition are discussed as discriminating criteria which cut across the verbal/non-verbal distinction. A possible model for the formation of integrated verbal/non-verbal scientific discourse is also suggested.

Le discours scientifique écrit, surtout en ingénierie, technologie et différents autres domaines des sciences dures, a souvent recours à des éléments partiellement verbaux ou non verbaux dans la représentation du savoir. Ces éléments coexistent au sein de blocs compacts de texte ou à leur périphérie. L'article étudie certains aspects de la dynamique intégrative entre des composants de nature différente et la spécificité du discours qu'ils engendrent. Les notions de connexité pragmatique/rhétorique, de discours rigides ou flexibles, et de modes d'exposition littéraux ou non littéraux sont abordées en tant que critères qui transcendent la distinction verbal/nonverbal. Un éventuel modèle pour la formation du discours scientifique intégrant verbal et nonverbal est aussi suggéré.

\section{INDEX}

Mots-clés: cohérence, cohésion, discours scientifique écrit, intégration, pragmatique, rhétorique, sémiologie, verbal, visuel

Keywords: coherence, cohesion, integration, pragmatics, rhetoric, semiology, verbal, visual, written scientific discourse 


\section{AUTHOR}

\section{CLAUDE SIONIS}

Claude Sionis est maître de conférences HDR en sciences du langage à l'Université de Nantes, IUT de Saint Nazaire. claude.sionis@wanadoo.fr 